\title{
STATISTICAL CHARACTERISTICS OF AEROSOL EXTINCTION COEFFICIENT PROFILE IN EAST ASIA FROM CALIPSO
}

\author{
Xuejin Sun, Junhao Zhou, Yongbo Zhou* \\ College of Meteorology and Oceanpgraphy, PLA University of Science \& Technology, \\ Nanjing 211101, China,*Email: dingboluo@yahoo.com
}

\begin{abstract}
Aerosol extinction coefficient profile (ECP) is important in radiative transfer modeling, however, knowledge of ECP in some area has not been clearly recognized. To get a full understanding of statistical characteristics of ECP in three Asian regions: the Mongolian Plateau, the North China Plain and the Yellow Sea, CALIPSO aerosol product in 2012 is processed by conventional statistical methods. Orbit averaged ECP turns out to be mainly exponential and Gaussian patterns. Curve fitting shows that the two ECP patterns account for more than 50 percent of all the samples, especially in the Yellow Sea where the frequency of occurrence even reaches over 80 percent. Parameters determining fitting curves are provided consequently. To be specific, Gaussian pattern is the main ECP distribution in the Mongolian Plateau and the Yellow Sea, and exponential pattern predominates in the North China Plain. Besides, aerosol scale height reaches its maximum in summer and in the Mongolian Plateau. Meanwhile, the uplifting and deposition of dust during transportation are potentially explanations to the occurrence of Gaussian ECP. The results have certain representativeness, and contribute to reducing uncertainties of aerosol model in relevant researches.
\end{abstract}

\section{INTRODUCTION}

Aerosol extinction coefficient profile (ECP) is one of the most uncertain factors in radiation transfer modeling. With the deployment of lidar in atmosphere detection, measurement of ECP becomes feasible, and achievements have been made in characterizing statistical characteristics of ECP in certain areas ${ }^{[1]}$. However, existing researches are usually confined to depict ECP qualitatively ${ }^{[2 \sim 3]}$. Besides, knowledge of ECP in certain areas remains scarce. In this study, three
Asian regions are selected: the Mongolian Plateau $\left(38 \sim 44^{\circ} \mathrm{N} ; 98 \sim 110^{\circ} \mathrm{E}\right)$, the North China Plain $\left(33 \sim 44^{\circ} \mathrm{N} ; 111 \sim 119^{\circ} \mathrm{E}\right)$ and the Yellow Sea $\left(31 \sim 38^{\circ} \mathrm{N} ; 121 \sim 127^{\circ} \mathrm{E}\right)$, which are denoted as A, $\mathrm{B}$ and $\mathrm{C}$ (black boxes in Fig. 1). They are regions where ground-based lidar station is sparse, therefore, relevant researches are rare. The results provide a full understanding of ECP in the three regions. More details are given below.

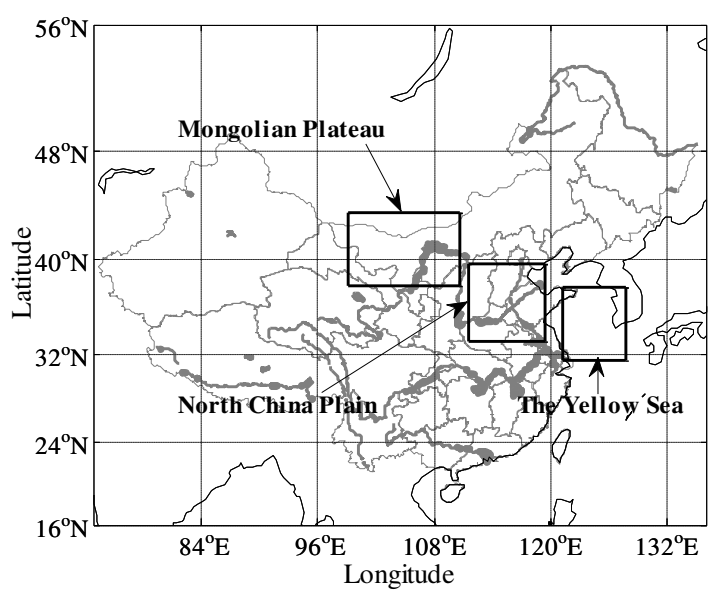

Fig. 1 Locations of selected regions

\section{METHODOLOGY}

\subsection{CALIPSO DATA}

CALIPSO aerosol product in 2012 is used to explore the statistical properties of ECP in the selected regions. CALIPSO is a member of the A-Train constellation of satellites which make global observation of ECP feasible ${ }^{[4]}$. Borne on CALIPSO, the Cloud-Aerosol Lidar with Orthogonal Polarization (CALIOP) provides aerosol product containing information on ECP and aerosol type. The product is gridded at a vertical resolution of $30 \mathrm{~m}$ below $8.2 \mathrm{~km}^{[5]}$, and correlates well with ground-based lidar ${ }^{[6]}$.

\subsection{STATISTICAL METHODS}

Orbit averaged ECP is generated by averaging valid data per layer in the selected regions. Besides, aerosol scale height and aerosol type are investigated. Aerosol scale height is defined as 
the height below which AOD reaches 63 percent of the whole-layer $\mathrm{AOD}^{[2]}$. In CALIPSO aerosol product, aerosol is classified into six types: clean marine, dust, polluted continental, clean continental, polluted dust and smoke. Aerosol per layer is interpreted as one of the six types, and the frequency of occurrence for each aerosol type is generated

\section{RESULTS}

Polynomial curve fitting is performed to the orbit averaged ECP whose valid layers surpass 50 percent of the whole layers below $10 \mathrm{~km}$. If the fitting rate of orbit averaged ECP to (1) or (2) is larger than 0.6, orbit averaged ECP is deemed as the pattern corresponding to the larger fitting rate.

$$
\begin{aligned}
& k(z)=a \cdot \exp (-b \cdot z)+c \\
& k(z)=a \cdot \exp \left[-\left(\frac{b-z}{c}\right)^{2}\right]+d
\end{aligned}
$$

where $k(z)$ denotes ECP. Curve fitting shows that the two ECP patterns account for more than 50 percent of all the ECP samples. For the Yellow Sea, the percentage even reaches over 80 percent (Fig.2).

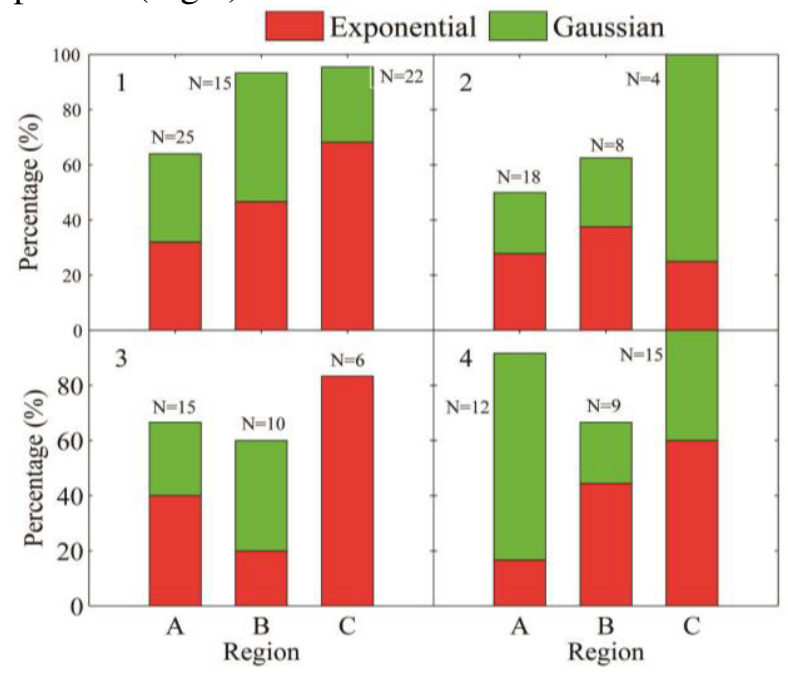

Fig. 2 Occurrence frequency for different ECP patterns. 1-4 in the top left corner denotes season from spring to winter. $\mathrm{N}$ is the the total number of profiles

Orbit averaged ECP with AOD larger than 0.4 only occurs in spring and winter in the Mongolian Plateau, while can be found in spring, summer and winter in the Yellow Sea and all year round in the North China Plain. In the Mongolian Plateau, scale height reaches its maximum in summer. In the North China Plain, aerosol scale height remains $2 \sim 3 \mathrm{~km}$. Scale height reaches its maximum and minimum in summer and winter for AOD between 0.6 0.8. For orbit averaged ECP with extremely large AOD (AOD > 0.8), variation of scale height with season is contrary to that of AOD within 0.6 0.8. In the Yellow Sea, scale height generally reaches its maximum in summer (Fig. 3).
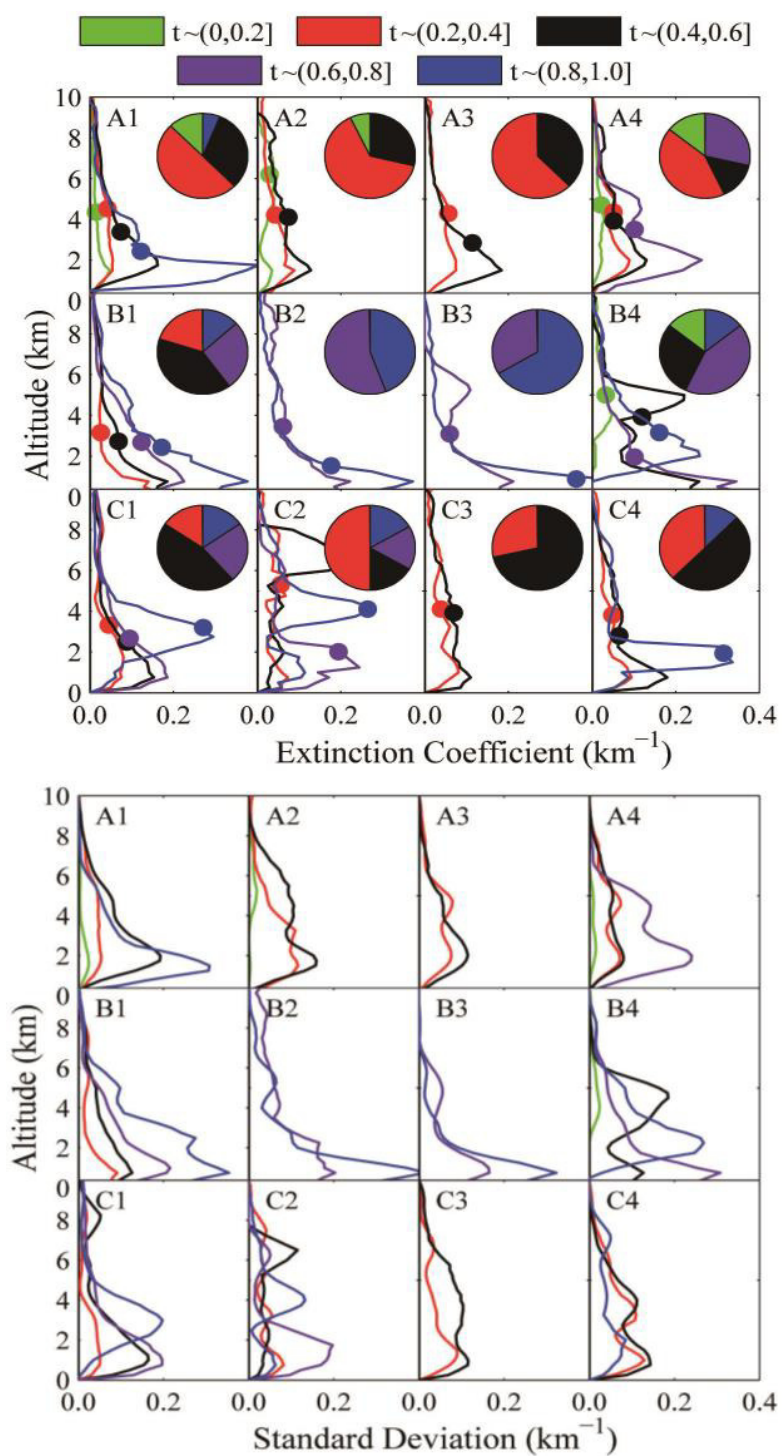

Fig. 3 The upper panel denotes orbit averaged ECP at 532-nm, where the inner pie charts indicate occurrence frequency for different AOD bins, and the colored rounds represent the scale height. The lower panel denotes standard deviation of orbit averaged ECP shown in upper panel. 1-4 in the top left corner denotes season from spring to winter, and A-C represents the three selected regions 
According to (1) and (2), Gaussian and exponential patterns are shaped by 4 and 3 parameters, which are presented as $\mathrm{G}(\mathrm{a}, \mathrm{b}, \mathrm{c}, \mathrm{d})$ and $\mathrm{E}(\mathrm{a}, \mathrm{b}, \mathrm{c})$ in Table $1-5$.

Table 1 ECP parameters for AOD below 0.2

\begin{tabular}{ccclc}
\hline & Spring & Summer & Autumn & winter \\
\hline A & $\mathrm{G}(0.03,1.6,1.2,0.01)$ & - & No data & - \\
B & No data & No data & No data & - \\
C & No data & No data & No data & No data \\
\hline
\end{tabular}

Table 2 ECP parameters for AOD between 0.2 and 0.4

\begin{tabular}{ccccc}
\hline & Spring & Summer & Autumn & winter \\
\hline A & $\mathrm{G}(0.04,3.1,2.9,0.01)$ & $\mathrm{G}(0.06,2.3,2.6,0.02)$ & $\mathrm{G}(0.05,2.8,2.7,0.01)$ & $\mathrm{G}(0.06,2.8,2.9,0.01)$ \\
B & $\mathrm{E}(0.20,1.1,0.0)$ & No data & No data & No data \\
C & $\mathrm{G}(0.06,1.6,1.6,0.02)$ & - & - & $\mathrm{E}(0.09,0.2,0)$ \\
\hline
\end{tabular}

Table 3 ECP parameters for AOD between 0.4 and 0.6

\begin{tabular}{ccccc}
\hline & Spring & Summer & Autumn & winter \\
\hline A & $\mathrm{G}(0.13,2.2,1.2,0.03)$ & $\mathrm{G}(0.08,1.7,0.8,0.05)$ & $\mathrm{G}(0.15,1.9,1.5,0.02)$ & $\mathrm{G}(0.09,2.4,1.5,0.03)$ \\
B & $\mathrm{E}(0.19,0.4,0.0)$ & No data & No data & $\overline{\mathrm{G}(0.18,0.2,0)}$ \\
C & $\mathrm{E}(0.17,0.3,0.0)$ & - & - & - \\
\hline
\end{tabular}

Table 4 ECP parameters for AOD between 0.6 and 0.8

\begin{tabular}{ccccc}
\hline & Spring & Summer & Autumn & winter \\
\hline A & No data & No data & No data & $\mathrm{G}(0.18,2.3,2.1,0.02)$ \\
B & $\mathrm{E}(0.29,0.2,0)$ & $\mathrm{E}(0.21,0.5,0.0)$ & $\mathrm{E}(0.18,0.5,0.0)$ & $\mathrm{E}(0.42,0.7,0.0)$ \\
C & $\mathrm{E}(0.21,0.3,0)$ & $\mathrm{G}(0.20,1.4,1.1,0.03)$ & No data & No data \\
\hline
\end{tabular}

Table 5 ECP parameters for AOD between 0.8 and 1.0

\begin{tabular}{ccccc}
\hline & Spring & Summer & Autumn & winter \\
\hline A & $\mathrm{G}(0.33,1.4,0.9,0.04)$ & No data & No data & No data \\
B & $\mathrm{E}(0.42,0.3,0)$ & $\mathrm{E}(0.41,0.6,0.0)$ & $\mathrm{G}(0.71,0.9,0.0)$ & $\mathrm{G}(0.21,2.5,1.4,0.03)$ \\
C & - & - & No data & $\mathrm{G}(0.33,1.8,0.7,0.04)$ \\
\hline
\end{tabular}

\section{CONCLUSIONS AND DISCUSSIONS}

In general, Gaussian pattern is the predominant ECP pattern in the Mongolian Plateau and the Yellow Sea, and exponential pattern predominates in the North China Plain.

In the Mongolian Plateau, dust and polluted dust are the main aerosol types in spring and winter, during sand-dust weather conditions, dust aerosol can stretch to upper troposphere ${ }^{[7]}$, the uplifting of dust aerosol may concentrate and forms a single peak of extinction coefficient at a certain layer, which is the typical characteristic of Gaussian distribution, which may be potential explanations to the prevalence of Gaussian pattern. In the Yellow Sea, aerosol is a mixture of clean marine, dust, polluted dust and smoke, of which clean marine aerosol only concentrates in lower layer in summer and autumn, namely, aerosol in this region is mainly transported from outer place. In summer and autumn, clean marine aerosol frequently occurs due to sea water evaporation. Clean marine aerosol is generally smaller than dust in particle size, which weakens extinction effect. Apart from these, aerosol in lower layer could be deposited into the ocean during longrange transportation, the remaining part may concentrates at a high layer, which is also typical characteristics of Gaussian pattern. The North China Plain is usually under the effect of smoke, dust and polluted dust, besides, seasonal variation of aerosol type is complex, accordingly, factors contributing to the predominance of Exponential distribution remain unclear. More details are shown in Fig. 4. 


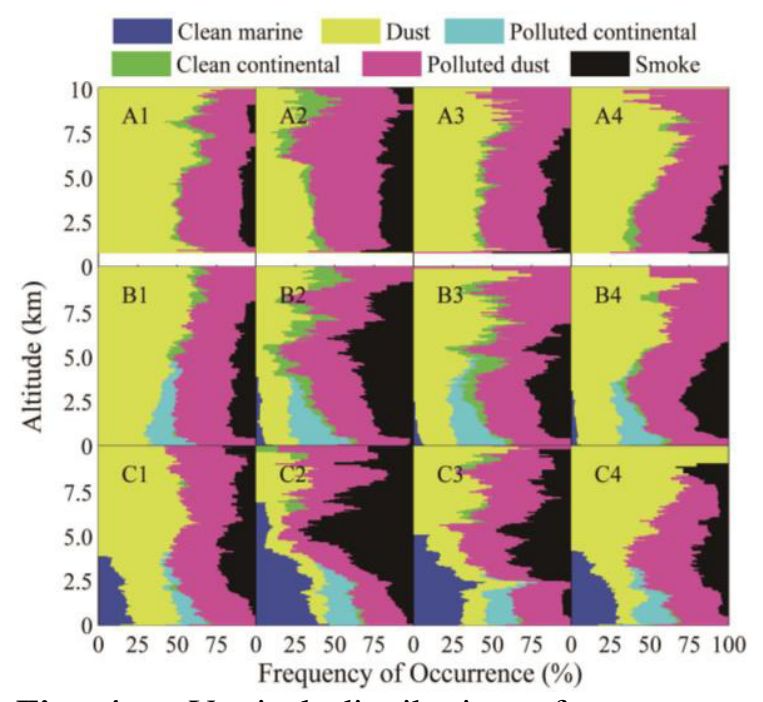

Fig. 4 Vertical distribution of occurrence frequency for each aerosol type. Characters in the top left corner have the same meanings as that of Fig. 3

The predominant ECP patterns in the three selected regions have certain representativeness, and they help to reduce uncertainties in aerosol model in relevant researches. However, it is noteworthy that ECP is a comprehensive function of many factors including geography, synoptic circulation et al. Therefore, further researches should focus on validation of ECP patterns through systematical analyses and measurements.

\section{ACKNOWLEDGEMENT}

We owe our thanks to the NASA Langley Atmospheric Science Data Center (ASDC) for its help in elaborating and providing the CALIPSO aerosol product.

\section{REFERENCES}

[1] Xu, C., Ge, J, Huang, J., Fu, Q., Liu, H., Chen, B., 2014: Observations of dust aerosol over China based on CALIPSO spaceborne lidar, J. Desert Res., 34(5), 1253-1362.

[2] Turner, D. D., Ferrare, R. A., Brasseur, L. A, 2001: Average aerosol extinction and water vapor profiles over the Southern Great Plains, Geophys. Res. Lett., 28(23), 4441-4444.

[3] Zhang, J., Li, X., 2012: Vertical distribution of sand-dust aerosols and the relationships with atmospheric environment, J. Arid Land, 4(4), 357-368.

[4] Yu, H., Chin, M., Winker, D. M., Omar, A. H., Liu, Z., Kittaka, C., Diehl, T. ,2010): Global view of aerosol vertical distributions from CALIPSO lidar measurements and GOCART simulations: Regional and seasonal variations, $J$. Geophys. Res.: Atmospheres, 115(D4): 19842012.

[5] Winker, D. M., Vaughan, M. A., Omar, A., Hu, Y., Powell, K. A., Liu, Z., Hunt, W. H., Young, S. A., 2009: Overview of the CALIPSO mission and CALIOP data processing algorithms, J. Atmos. Ocean. Tech., 26(11), 2310-2323.

[6] Wu, Y., Cordero, L., Gross, B., Moshary, F., Ahmed, S., 2014: Assessment of CALIPSO attenuated backscatter and aerosol retrievals with a combined ground-based multiwavelength lidar and sunphotometer measurement, Atmos. Environ., 84, 44-53.

[7] Huang, J., Minnis, P., Chen, B., Huang, Z., Liu, Z., Zhao, Y., Yi, Y., Ayers J. K., 2008: Long-range transport and vertical structure of Asian dust from CALIPSO and surface measurements during PACDEX. J. Geophys. Res., 113( D23212), 1-13 